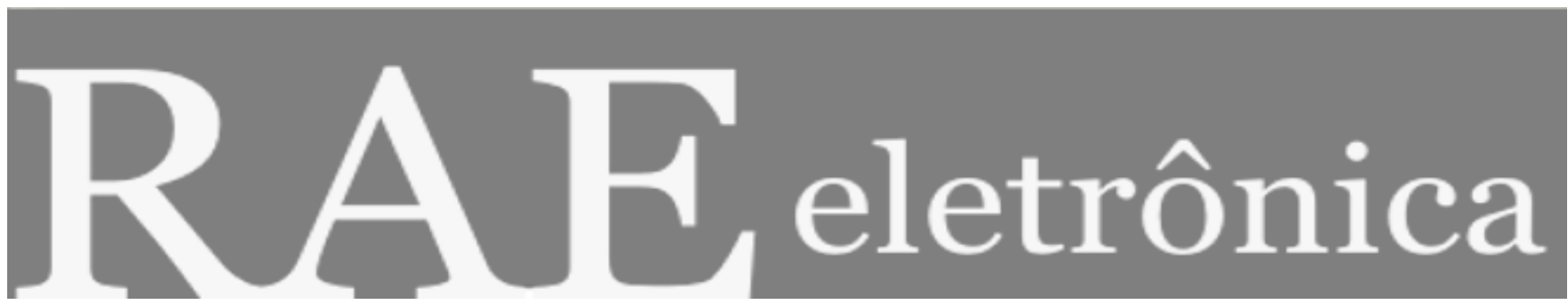

\title{
BALANÇO SOCIAL COMO INSTRUMENTO DE MARKETING
}

Por:

Fernando Augusto Trevisan

RAE-eletrônica, Volume 1, Número 2, jul-dez/2002.

http://www.rae.com.br/eletronica/index.cfm?FuseAction=Artigo \&ID=1465\&Secao=PWC\&Volume=1 $\&$ Numero $=2 \& A n o=2002$

CCopyright, 2002, RAE-eletrônica. Todos os direitos, inclusive de tradução, são reservados. É permitido citar parte de artigos sem autorização prévia desde que seja identificada a fonte. A reprodução total de artigos é proibida. Os artigos só devem ser usados para uso pessoal e nãocomercial. Em caso de dúvidas, consulte a redação: redacao@rae.com.br.

A RAE-eletrônica é a revista on-line da FGV-EAESP, totalmente aberta e criada com o objetivo de agilizar a veiculação de trabalhos inéditos. Lançada em janeiro de 2002, com perfil acadêmico, é dedicada a professores, pesquisadores e estudantes. Para mais informações consulte o site www.rae.com.br/eletronica.

RAE-eletrônica

ISSN 1676-5648

(C)2002 Editora: Fundação Getulio Vargas - Escola de Administração de Empresas de São Paulo.

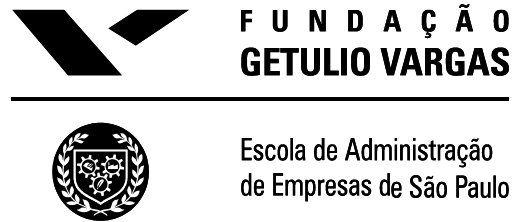




\title{
BALANÇO SOCIAL COMO INSTRUMENTO DE MARKETING
}

"Se queremos progredir, não devemos repetir a história, mas fazer uma história nova." Mahatma Gandhi

\section{Fernando Augusto Trevisan}

Graduado em Administração de Empresas pela FGV-EAESP e Graduado em Jornalismo pela PUC SP.

E-mail:fetrevisan@hotmail.com

\section{RESUMO}

A ampla difusão de informações no mundo atual leva a uma commoditização dos produtos. Com isso, as empresas precisam buscar novas formas de diferenciação. $\mathrm{O}$ artigo que segue tem o objetivo de mostrar a importância da prática da responsabilidade social pelas empresas e da divulgação de suas atividades sociais por meio do Balanço Social. O trabalho foi feito a partir de pesquisas e leituras de artigos de personalidades representativas do tema no Brasil. Constatou-se que há um movimento cada vez maior das empresas no sentido de arcar com responsabilidades em relação a seus funcionários, clientes, fornecedores, acionistas, à comunidade onde atuam e ao meio ambiente. Além disso, a atuação social cresce em importância no processo decisório de compra, na medida em que os consumidores estão mais atentos ao grau de cidadania que aquele produto ou serviço representa. Daí conclui-se que o Balanço Social pode ser utilizado pelos executivos como um elemento estratégico na gestão do Marketing.

\begin{abstract}
The huge spread of information in nowadays' world leads society into the commoditization of products. Therefore, companies need to seek new forms of differentiation. The main objective of the following article is to show the importance of the social responsibility practice by companies and of proving their social activities to the public through the Social Balance Sheet. This work was done based on research and reading of articles written by representative Brazilian personalities on the subject in question. From such data it could be identified that there is a growing number of companies moving towards assuming responsibilities related to their employees, clients, suppliers, stockholders, to the community where they act and to the environment. Besides, social actions have increased importance in the decision making process of purchase, as the awareness of consumers to the degree of citizenship that certain products or services represent rise. In the light of such, the conclusion that is reached is that the Social Balance Sheet can be used by executives as a strategic tool to Marketing management.
\end{abstract}

\section{PALAVRAS-CHAVE}

Balanço social, responsabilidade social, marketing social, filantropia estratégica, diferenciação.

\section{KEY-WORDS}

Social balance sheet, social responsibility, social marketing, strategic philantropy, difereciation. 


\section{INTRODUÇÃO}

Em uma época de globalização feroz, onde a troca de informação atinge um nível nunca antes alcançado, os produtos se tornam cada vez mais iguais. O conhecimento está muito mais disponível para as empresas, e fazer um produto de qualidade já não é mais um diferencial. Dentro desse cenário, o que define o sucesso de uma empresa e o aumento de seu faturamento pode estar relacionado com o que a sua imagem sugere e conota para o consumidor. "Hoje, o patrimônio empresarial se constrói com uma marca forte que, por sua vez, está diretamente relacionada às atitudes da empresa", afirma Guilherme Leal, presidente da Natura Cosméticos (D’AMBROSIO, 1998). Uma empresa que realiza projetos sociais possui uma vantagem competitiva que deve ser gerenciada no âmbito estratégico por seus executivos.

O conceito de responsabilidade social nas empresas é bastante difundido na maioria dos países desenvolvidos. No Brasil, a preocupação dos empresários em contribuir para o bem-estar da sociedade ainda é relativamente pequena. No entanto, se observa um movimento cada vez maior das empresas no sentido de arcar com responsabilidades em relação a seus funcionários, clientes, fornecedores, acionistas, à comunidade onde atuam e ao meio ambiente.

\section{RESPONSABILIDADE SOCIAL CORPORATIVA NO BRASIL}

Os dados consolidados da pesquisa "Ação Social das Empresas no Brasil" recentemente divulgada pelo Instituto de Pesquisa Econômica Aplicada (IPEA) indicam que 465 mil companhias no país exercitam a responsabilidade social corporativa. Já existe inclusive uma entidade no país cujo principal objetivo é implementar o conceito de ética e responsabilidade social entre o empresariado. O Instituto Ethos, criado em julho de 1998, já conta com mais de 430 empresas associadas, que respondem por cerca de $20 \%$ do PIB nacional, entre elas a Abril S/A, o Grupo Pão de Açúcar e a Petrobrás S/A.

Cada vez mais as empresas estão se defrontando com a necessidade de incorporar a responsabilidade social aos seus objetivos de lucro. A ação socialmente responsável das empresas já ultrapassou o estágio de mera tendência para se transformar gradativamente em estratégia corporativa.

Ao mesmo tempo, a empresa socialmente responsável tem o direito de mostrar ao público o que vem fazendo na área social e o que oferece de retorno à comunidade onde está instalada. Para divulgar essas ações, um dos melhores instrumentos é o Balanço Social; ele aproxima a organização da comunidade em que está instalada e com a qual compartilha o meio ambiente e as riquezas necessárias para sua operação. Para Sucupira (1999), o Balanço Social é "um conjunto de informações sobre as atividades desenvolvidas por uma empresa, em promoção humana e social, dirigidas a seus empregados e à comunidade onde está inserida. Através dele a empresa mostra o que faz pelos seus empregados, dependentes e pela população que recebe sua influência direta".

Esse demonstrativo deve permitir visualizar as atividades sociais desenvolvidas pela empresa, desde a evolução dos empregos e os treinamentos até a proteção ao meio ambiente, a preservação de bens culturais e a utilização dos lucros da empresa, dando condições para que a comunidade possa identificar aquela empresa que causa danos sociais ou não agrega valor à sociedade. "O Balanço Social tem por objetivo demonstrar o resultado da interação da empresa com o meio em que está inserida, o grau de responsabilidade social assumido e assim prestar contas à sociedade pelo uso do patrimônio 
público, constituído por recursos naturais, humanos e o direito de conviver e usufruir dos benefícios da sociedade em que atua" (IUDÍCIBUS, 2000).

Por meio do Balanço Social, fornecedores, investidores e consumidores têm uma radiografia de como a empresa encara suas responsabilidades públicas, aspecto cada vez mais relevante no processo de decisão de compra. Em um recente estudo chamado Millenium Poll realizado em 23 países e publicado no site da organização internacional Business for Social Responsability (BSR), $90 \%$ das pessoas entrevistadas declararam que esperam algo mais das empresas além dos produtos ou serviços que prestam aos consumidores. "Empresa que cumpre seu papel social possui a capacidade de atrair maior quantidade de consumidores" (CAMARGO, 2001).

"Essa expectativa reflete uma mudança progressiva no papel das companhias, onde se espera delas retorno à comunidade face ao lucro obtido com os negócios. (...) A realidade é que na nova configuração social todos os papéis estão sendo revistos e, tanto as empresas, quanto a sociedade civil assumem cada vez maiores responsabilidades perante a comunidade" (BAGGIO, 1999). Acaba-se criando, portanto, um intercâmbio jamais visto entre agentes que antes atuavam isoladamente.

Assim, aumenta-se a responsabilidade de as empresas prestarem contas ao público no que diz respeito a sua atuação social. Conforme Camargo (2001), o Balanço Social faz parte do processo de pôr as cartas na mesa e mostrar com transparência para o público em geral, para os atentos consumidores e para os acionistas e investidores o que a empresa está fazendo na área social. É ainda um instrumento facilitador e multiplicador do processo de consolidação da responsabilidade social das empresas.

\section{HISTÓRICO DO BALANÇO SOCIAL}

No início do século XX já se constatava a existência de manifestações a favor de uma maior responsabilidade social nas empresas. Entretanto, foi somente a partir dos anos 60 nos Estados Unidos e no início da década de 70 na Europa - particularmente na França, Alemanha e Inglaterra - que a sociedade iniciou uma cobrança deste tipo de comportamento por parte do empresariado e consolidouse a própria necessidade de divulgação dos chamados balanços ou relatórios sociais.

A companhia alemã Steag foi a primeira empresa, em 1971, a produzir uma espécie de relatório sobre suas atividades sociais. Porém, o que pode ser classificado como um marco na história dos balanços sociais, no seu sentido pleno, aconteceu na França em 1972: a empresa Singer fez o, assim chamado, primeiro Balanço Social da história das empresas. Neste país, várias experiências consolidaram a necessidade de uma avaliação mais sistemática por parte das empresas no âmbito social. Até que em 1977, foi aprovada uma lei que tornava obrigatória a realização de balanços sociais periódicos para todas as empresas com mais de 700 funcionários, número que posteriormente baixou para 300 .

No Brasil, a influência desta mudança de mentalidade empresarial já pôde ser notado na "Carta de Princípios do Dirigente Cristão de Empresas", publicada em 1965, pela Associação de Dirigentes Cristãos de Empresas do Brasil (ADCE Brasil). Na década de 80, a Fundação Instituto de Desenvolvimento Empresarial e Social (FIDES) chegou a elaborar um modelo de divulgação das atividades sociais. Porém, só a partir do início dos anos 90 é que algumas empresas - muito poucas passaram a levar a sério esta questão e a divulgar sistematicamente em balanços e relatórios sociais as ações realizadas em relação à comunidade, ao meio ambiente e ao seu próprio corpo de funcionários. 
O primeiro Balanço Social feito no Brasil foi da Nitrofértil, empresa estatal situada na Bahia, em 1984. A curiosidade deste balanço é que ele também foi apresentado no estilo de literatura de cordel. No mesmo período, estava sendo realizado o Balanço Social do Sistema Telebrás, publicado em meados da década de 80. O do Banespa, realizado em 1992, completa a lista das empresas precursoras deste tipo de relatório no Brasil. Depois de recolocado na agenda nacional a partir de 1997 em um amplo seminário realizado no Centro Cultural Banco do Brasil (CCBB, Rio de Janeiro), o tema da responsabilidade social das empresas e do Balanço Social voltou a pautar imprensa, empresas, universidades e organizações do terceiro setor. Atualmente, a publicação do Balanço Social é obrigatória por lei na França, e em países como Estados Unidos, Bélgica e Alemanha ela ocorre por exigência da própria sociedade.

\section{A CORRETA UTILIZAÇÃO DO BALANÇO SOCIAL}

Não se pode confundir, contudo, Balanço Social com política de recursos humanos interna. Esta cuida apenas da relação da empresa com seus funcionários, enquanto que aquele se preocupa também com os feitos da empresa em relação à sociedade externa a ela, ou seja, desde investidores e fornecedores até meio ambiente e Estado. "O Balanço Social, como estratégia de mudança, de impacto eminentemente social e cultural, tem por objeto demonstrar ao universo de usuários, de forma confiável, uma prestação de contas, para que possam conhecer e avaliar a qualidade dos investimentos, aplicação de recursos e o cumprimento das destinações orçamentárias" (BATISTA, 2000).

Assim como o Balanço Contábil, o Balanço Social necessita ainda estar suplantado em dados concretos e mensuráveis para que tenha credibilidade. "Para a elaboração do Balanço Social, a premissa é idêntica: em relação aos dados que compõem a Demonstração do Balanço Social, de ordem quantitativa ou qualitativa, seja qual for a relevância dos investimentos tangíveis ou intangíveis, a confirmação dos elementos dar-se-á sempre via contabilidade. Caso contrário, o Balanço Social não passa de mera peça ilustrativa de veracidade questionável ou de marketing" (BATISTA, 2000).

A empresa que utiliza um programa social para explorar grupos ou causas sociais por meio da comunicação inadequada certamente será facilmente identificada pelo mercado como desonesta e hipócrita e terá sua marca seriamente prejudicada. Isso porque "a organização mais ética do espaço econômico decorre da percepção de que padrões de comportamento meramente oportunistas terminam por ser insustentáveis" (AZAMBUJA, 2001).

É exatamente para garantir que os dados apresentados no Balanço Social sejam um retrato fiel da realidade da empresa naquele período e para evitar um eventual descrédito junto ao mercado que Gonçalves (1980, p.32), através de Robert Taylor, afirma que "(...) é recomendável que as empresas, que por primeira vez decidem efetuar um Balanço Social, não o publiquem. Podem e devem fazê-lo com a participação do pessoal, porém deve ficar perfeitamente claro que é um instrumento interno". Num primeiro momento, a organização deve, portanto, se utilizar do Balanço Social para tomar decisões estratégicas no âmbito interno principalmente. "Se ela já começar a divulgá-lo, antes de uma análise dos seus resultados, poderá ter um retorno indesejável, pois as mais diversas interpretações poderão surgir do ambiente externo. $\mathrm{O}$ ideal é utilizar as informações contidas neste demonstrativo para aparar as arestas internas, e só posteriormente divulgá-las à sociedade, ou, ainda, ter um modelo especial de Balanço Social para fins gerenciais internos” (BATISTA, 2000).

Vale lembrar ainda que ser socialmente responsável não é assumir uma postura assistencialista, ou seja, fazer doações em dinheiro ou de bens, porque isso não minimiza as dificuldades de uma pessoa nem de 
uma comunidade. "Num momento de crise, ninguém se satisfaz a não ser que receba orientação e seja educado para começar a reagir contra a crise. $\mathrm{O}$ assistencialismo, às vezes, não passa de um momento de lucidez de um empresário, em assinar um cheque e doar para que outra pessoa usufrua daquele benefício. A responsabilidade social vai mais além. A companhia provém o recurso, abraça um projeto, mas antes define com seus colaboradores onde será aplicado e como poderá ser melhorado", afirma Alberto Augusto Perazzo, presidente-executivo da FIDES.

\section{UM INSTRUMENTO DE CIDADANIA CORPORATIVA}

O lucro das empresas é um importante instrumento não só de sobrevivência das empresas, mas também de medição do sucesso que tiveram em atender a necessidades de bens e serviços da sociedade. "Muitos aspectos da vida da empresa fogem às simples considerações contábeis. Os resultados demonstrados no balanço econômico podem parecer brilhantes e promissores e, contudo, os verdadeiros objetivos da empresa talvez não tenham sido atingidos" (HUMES, 1999). Se a empresa for considerada apenas um instrumento de geração de riquezas materiais e se, como resultado, todas as pessoas que a ela estão ligadas e todas as ações por ela empreendidas forem subordinadas a esse único propósito, os objetivos maiores da empresa estarão sendo esquecidos.

"Se admitirmos, com efeito, que são os homens e as mulheres que constituem o patrimônio mais precioso da empresa, a satisfação das necessidades fundamentais destes passa a ter importância indeclinável" (HUMES, 1999). Este é o princípio da empresa-cidadã, ou seja, aquela que é comprometida com a qualidade de vida da sociedade e que, através do seu Balanço Social, apresenta os seus investimentos nos mais diversos projetos sócio-culturais.

"As empresas que tomaram a decisão de investir na melhoria comunitária, ou seja, que levaram em consideração a sua responsabilidade social, estão rapidamente descobrindo o sucesso do negócio. Elas praticam a responsabilidade social da mesma forma com que utilizam estratégias para obter lucro com produtos de qualidade" (BATISTA, 2001).

\section{TRATAMENTO PADRONIZADO E PROFISSIONAL DAS INFORMAÇÕES}

Em 1997, o Instituto Brasileiro de Análises Sociais e Econômicas (Ibase), em parceria com o sociólogo Herbert de Souza, iniciou uma forte campanha com o objetivo de chamar à atenção dos empresários e de toda a sociedade para a importância e a necessidade da realização do Balanço Social das empresas. Esse movimento resultou no projeto de lei 3116/97 das deputadas federais Marta Suplicy, Maria da Conceição Tavares e Sandra Starling. De acordo com esse projeto, empresas com 100 empregados ou mais seriam obrigadas a publicar o Balanço Social; as que não fizessem estariam sujeitas a multas, ficariam impedidas de participar de licitações e contratos de administração pública, bem como de se beneficiarem de incentivos fiscais e de programas oficiais de crédito. Em parceria com diversos representantes de empresas públicas e privadas, o Ibase desenvolveu um modelo simples de Balanço Social para organizar e promover esse tipo de atuação no Brasil.

Sabendo da importância de as empresas disponibilizarem cada vez mais informações de valor para a sociedade, inclusive para alavancar suas vendas, o Instituto criou também o "Selo Balanço Social Ibase/Betinho", que passou a ser concedido às empresas que realizaram seus balanços no modelo sugerido. Das 102 empresas que publicam anualmente o documento no Brasil, 66 delas utilizam o 
modelo sugerido, e a metade destas já receberam o "Selo Balanço Social Ibase/Betinho". Assim como o selo "Empresa Amiga da Criança" da Fundação Abrinq identifica com clareza aquelas organizações engajadas na melhoria da situação da criança, o do Ibase está se tornando também um elemento concreto de vantagem competitiva das empresas. O Balanço Social valoriza a cidadania, além de mapear e avaliar o desempenho social da empresa e, portanto, deve ser encarado também como um instrumento estratégico de Marketing.

\section{MARKETING SOCIAL: UMA QUESTÃO DE FOCO}

Cresce em todo o mundo a preocupação com a questão social e ambiental, na medida em que está se chegando em um ponto crucial, principalmente nos países não-desenvolvidos como o Brasil. O meio empresarial, parte integrante e ativa dentro dessa realidade, busca formas de melhorar seu relacionamento com o meio ambiente e a sociedade, de modo a contribuir para o desenvolvimento social e econômico, do qual dependem para sua própria sobrevivência. "Quanto mais oportunidades para as pessoas, melhor para os negócios", afirma Stephan Schmidheiny, presidente do Conselho Mundial empresarial para o Desenvolvimento Sustentável (ECONÔMICO, 2002).

E as organizações que utilizarem de maneira inteligente essa atuação social em sua estratégia de comunicação, vão sair na frente das outras. As primeiras empresas a investir no marketing social serão as primeiras a abraçar as causas de maior impacto, as "melhores causas", sob o ponto de vista do marketing. Os retardatários nesse processo ficarão com as causas de menor impacto ou terão a necessidade de pesquisar constantemente para descobrir novas oportunidades.

Diferentemente de uma política de doações ou de assistencialismo aleatório, que pode gerar dificuldades para o consumidor associar a imagem da empresa a um projeto social específico, o marketing social visa definir a correta aplicação dos recursos em uma causa determinada, de modo a tornar essa atuação social mais eficiente e criar uma identidade perante o público. É o que Stephen Kanitz, diretor da Kanitz \& Associados e colunista da revista Veja, chama de "filantropia estratégica". Para ele, a empresa deve primeiramente conhecer o enorme leque de necessidades sociais que carecem de apoio governamental e depois optar por aquelas que correspondem a suas competências e interesses de seus funcionários. "Grandes empresas descobrirão que apoiar um ou outro evento beneficente dirigido pelo departamento de marketing não dá bons resultados. Os consumidores e a opinião pública percebem o tom mercadológico de certas iniciativas", escreve ele em seu site na Internet. "A filantropia estratégica definida claramente pela companhia ganha credibilidade e seriedade." De acordo com o texto, as 500 maiores empresas brasileiras doam, aproximadamente, 300 milhões de dólares para entidades beneficentes, o que além de ser uma quantia irrisória para os padrões internacionais, é em sua maioria feita de forma totalmente descordenada, sem estratégia filantrópica definida.

Como diz Azambuja (2001), “a filantropia não pode nem deve eximir a empresa de suas responsabilidades. Por mais louvável que seja uma empresa construir uma creche ou um posto de saúde na sua comunidade, a sua generosidade em nada adiantará se, ao mesmo tempo, estiver poluindo o único rio local ou utilizando matéria-prima produzida em fábricas irregulares, que empregam trabalho infantil em condições insalubres ou perigosas".

Segundo Kanitz, com um pouco de análise encontra-se alguma sintonia entre as entidades, suas causas, competências e motivação de uma empresa. "Como a $C \& A$, por exemplo, que abraçou a educação infantil, já que a maior parte dos funcionários tem filhos e gostaria de entender de educação em geral", afirma. Outro exemplo é o Boticário, cuja imagem associada à preservação do meio ambiente já é 
bastante difundida e clara, além de ter a ver com suas competências como empresa do setor de cosméticos. A Latasa, que provoca poluição de latas de alumínio vazias, instituiu uma bem sucedida campanha beneficente que troca um certo número de latas vazias por equipamentos escolares. Dezenas de entidades beneficentes e escolas promovem campanhas de arrecadação de latas, já que estas são recicláveis e o custo da campanha e praticamente nulo. "Se a indústria do fumo tivesse empregado um décimo do que gasta em propaganda e em pesquisas para a cura do câncer do pulmão, sua posição seria bem mais confortável”, escreve Kanitz. "Ao negar que o problema existe acabou cavando sua própria sepultura."

A transparência e a cultura ética, no entanto, só chegam ao mercado e ao consumidor quando a empresa tem, de fato, uma política interna elaborada de acordo com esses princípios. "Empresas como a OPP Petroquímica, Merck Sharp \& Dohme e Hewlett Packard (HP) têm um código de ética, que é apresentado aos funcionários no momento da admissão e revistos a cada ano. Na HP, a revisão dos padrões de conduta nos negócios está entre uma das cobranças do processo de avaliação de desempenho. Os funcionários da empresa seguem normas rígidas de conduta, que não permitem, por exemplo, o recebimento de brindes com valor material representativo" (D’AMBROSIO, 1998)

\section{INFORMAÇÃO DISPONÍVEL AO PÚBLICO}

É importante que a empresa insira o consumidor no contexto de sua atuação social. "Para que ele possa cumprir sua responsabilidade social, deve ter informação e conhecimento" (ASHLEY, 2001). Daí a importância de um instrumento efetivo e crível de prestação de contas à comunidade como o Balanço Social. Sobre essa questão, a Deputada Marta Suplicy afirma, com muita propriedade, que "a informação é um dos pressupostos da cidadania. O Balanço Social é um instrumento de informação" (SUPLICY, 1997).

Notadamente nos dias de hoje, em que os dados se processam rapidamente, as informações contábeis que dão conta da vida econômica, financeira, física e produtiva de uma organização - são um sistema poderoso a serviço da tomada de decisão dentro e fora das organizações. Contudo, como diz Bernadette Coser de Orem, diretora-executiva da Fundação Otacílio Coser, o sistema tradicional de informações, voltado para o aspecto econômico, tornou-se insuficiente para oferecer dados agora imprescindíveis a essa nova configuração empresarial.

Cada vez menos as pessoas estão julgando uma empresa apenas por seus fatores econômicos. Segundo pesquisa promovida pelo Instituto Ethos e pelo jornal Valor Econômico, e conduzida pela Indicator Opinião Pública, 56\% dos 1002 brasileiros entrevistados consideram a responsabilidade social um elemento importante para dizer se a empresa é boa ou ruim. Além disso, $24 \%$ dos entrevistados disseram ter prestigiado uma empresa que acharam socialmente responsável, comprando seus produtos ou falando bem dela para outras pessoas, e 19\% disseram ter punido uma empresa em situação oposta fazendo o contrário. Outros dados ressaltam o fato de que os consumidores estão bem atentos às atitudes das empresas: 53\% disseram que deixariam de comprar produtos de uma empresa que utilizasse mão-de-obra infantil e 73\% disseram que não iriam mais adquirir produtos de uma empresa que estivesse envolvida em corrupção e pagamento de propinas a autoridades ou agentes públicos.

Atualmente, para ser competitiva e lucrar, a empresa precisa relacionar sua marca a conceitos e valores éticos. "Afinal, para conquistar o consumidor, que exerce com cada vez mais consciência a sua 
cidadania, as companhias precisam comprovar que adotam uma postura correta, tanto no que diz respeito às leis, aos direitos humanos e ao meio-ambiente, quanto na relação com funcionários, consumidores, fornecedores e clientes" (D’AMBROSIO, 1998).

A consciência crítica que se desenvolve na sociedade atual de uma forma geral obriga as empresas a assumirem um planejamento cada vez mais criterioso, especialmente quanto ao resultado de suas ações. Pode-se dizer que hoje em dia, a empresa que cumpre seu papel social deve atrair mais consumidores, além de estar investindo na sociedade e, por conseguinte, no seu próprio futuro. Assim, para além das poucas linhas que algumas empresas dedicam nos seus balanços patrimoniais e dos luxuosos modelos próprios de Balanço Social que estão surgindo, tornou-se necessária a sistematização desse processo.

Com o modelo único - simples e objetivo, criado pelo Ibase, vai ser possível avaliar o próprio desempenho da empresa na área social ao longo dos anos, e também comparar uma com outra. Além disso, a empresa tem o direito, antes do dever, de dar publicidade às suas ações. "Porém, esta propaganda será cada vez mais honesta e verdadeira", diz Ciro Torres. "Um modelo único vai na justa medida permitir a utilização de parâmetros iguais e a comparação por parte dos consumidores, investidores e da sociedade em geral."

\section{REGULAMENTAÇÃO DO BALANÇO SOCIAL NO BRASIL}

Há controvérsias em relação à regulamentação do balanço social no Brasil. A Associação Brasileira das Empresas de Capital Aberto (Abrasca), se manifestou contrária a este projeto de lei, caracterizando-a de retrógrada em relação à liberdade das empresas de apresentar ou não, explicitamente, sua contribuição social. A entidade acredita que tais informações podem ter caráter estratégico para a empresa, além de elevar os custos para sua elaboração. O contador Marco Antônio Perottoni também é contra a proposta, acreditando que a obrigatoriedade afronta o princípio fundamental da natureza liberal que regula as relações sociais (CARVALHO, 2000). A Comissão de Valores Imobiliários (CVM) emitiu pareceres favoráveis à elaboração do Balanço Social.

\section{O SOCIAL É ESTRATÉGICO}

Se a sociedade da comunicação é aquela que fornece às empresas os meios de crescimento globalizado, é também a mesma que lhes cobra uma postura mais comprometida com os efeitos deste crescimento. "Como conseqüência natural da evolução da empresa, num mundo onde a comunicação é valor e os efeitos da globalização pesam sobre a administração ao mesmo tempo em que a impulsionam para a transformação sistemática, surge a responsabilidade social empresarial como novo fator de desenvolvimento corporativo" (OREM, 1999).

Incorporada à estratégia de gestão administrativa, a prática da responsabilidade social, portanto, cresce para uma atuação cada vez mais ampla, fortalecendo o emergente Terceiro Setor. É inevitável nascer daí uma satisfação maior que se traduza na valorização da imagem da empresa e de seu produto. "Nada mais adequado para o mundo empresarial do que encontrar na responsabilidade social a solução que satisfaça os anseios da comunidade, ao mesmo tempo em que se agrega valor à corporação" (OREM, 1999). A demonstração de Valor Adicionado (DVA) - um apêndice normalmente sintético do balanço contábil de uma companhia que visa demonstrar o valor da riqueza gerada pela empresa - constitui inclusive um dos componentes do balanço social (DE LUCA, 1998). 
A participação social das empresas e a posterior divulgação dessas atividades para o público podem reverter em benefícios diretos como: conquista de lealdade dos clientes, aumento na estima dos colaboradores e retorno de imagem. Além disso, o governo, que é o maior comprador em termos de volume, prefere claramente negociar com empresas atuantes em causas sociais, já que é uma maneira de estimular e difundir estas práticas junto ao empresariado e diminuir a pressão social sobre ele.

Com relação ao comércio exterior, a utilização de mão-de-obra infantil, por exemplo, já é um aspecto que pode afetar diretamente a exportações nacionais. Os Estados Unidos aplicaram novas barreiras aos produtos brasileiros por razões sociais. O Senado norte-americano aprovou em 1999 uma lei que proíbe qualquer órgão do governo de comprar produtos que tenham participação de trabalho infantil ao longo da cadeia produtiva. E as barreiras podem valer mesmo dentro do Brasil. "A Embaixada dos Estados Unidos, por exemplo, não poderá comprar álcool brasileiro, porque há crianças trabalhando nos canaviais", alerta Oded Grajew, presidente do Instituto Ethos. "O trabalho infantil vai começar a pesar no bolso dos empresários brasileiros." Os setores de citros e calçados foram alertados pela Fundação Abring sobre o risco de perderem grandes encomendas no exterior por admitirem adolescentes com menos de 14 anos no processo produtivo.

\section{CONCLUSÃO}

Abraçar uma causa social e se tornar conhecido como o seu mantenedor é muito mais interessante do que praticar uma política de doações ao acaso, já que os esforços estarão concentrados em um mesmo problema ou necessidade. O marketing social tem a função de colocar a marca na empresa e não nos produtos; define a companhia como uma organização séria, um cidadão corporativo, uma empresa com conteúdo, com integridade. "Nesta era, devido ao culto à individualidade, empresas serão vistas e julgadas pelos mesmos padrões que costumamos julgar indivíduos", diz Stephen Kanitz. "Não pelo que você faz, mas pelo que você é."

Dessa forma, produtos e serviços de empresas que atuam junto ao Terceiro Setor passam a ser preferidos em detrimento a outros de mesma qualidade e preço. As pessoas podem cada vez mais optar por produtos da Santista porque ela promove o "Prêmio Santista" em prol da literatura nacional e deixar de comprar tênis da Nike por ela utilizar mão-de-obra infantil. O que vai diferenciar uma margarina ou um suco de laranja senão os projetos sociais com os quais esta ou aquela marca estão engajadas? Para causar uma boa impressão, os profissionais de marketing devem buscar formas mais baratas e eficientes que não aquela meramente relacionada ao produto.

O marketing de causa relacionada ou a filantropia estratégica representa uma oportunidade de diferenciação em um ambiente extremamente competitivo. O produto passa a agregar um valor de 'simpatia' para as pessoas que também consideram aquela causa relevante e, consequentemente, para os consumidores. Isso porque estes podem ver esse produto como uma oportunidade para apoiarem causas sociais de maneira simples por meio do uso ou da compra.

As ações sociais da empresa devem ser tratadas de modo cada vez mais profissional para assegurar a transparência daquilo a que ela se comprometeu, o que é justamente o que vai garantir uma boa imagem do mercado. Nesse contexto, o Balanço Social é o instrumento que efetivamente apresenta para o mercado e para a comunidade sua identidade social. Como diz Kroetz (1999), "o Balanço Social, antes de ser uma demonstração endereçada à sociedade, é considerada uma ferramenta gerencial, pois reúne dados qualitativos e quantitativos sobre as políticas administrativas, sobre as relações entidade/ambiente e outros, os quais poderão ser comparados e analisados de acordo com as 
necessidades dos usuários internos, servindo como instrumento de controle e de auxílio para a tomada de decisões e adoção de estratégias".

A atuação voltada para a sociedade, para a construção de valores, imagens e projetos coletivos está se tornando parte indissociável de uma empresa de sucesso. A prática social nas empresas é um negócio; pode e deve ser utilizada como instrumento de Marketing nos dias de hoje.

\section{Artigo recebido em 08.06.2001. Aprovado em 10.05.2002}

\section{REFERÊNCIAS BIBLIOGRÁFICAS}

ASHLEY, Patrícia A. A Ética e a Responsabilidade Social nos Negócios. São Paulo: Saraiva, 2001.

AZAMBUJA, Marcos de. O Brasil e a Cidadania Empresarial. Jornal Valor Econômico, São Paulo, ano 2, n. 244, 20 de abril de 2001.

BAGGIO, Roberto. Valor Econômico, julho de 1999

BATISTA, Halcima Melo. Balanço Social: Uma Mudança de Estratégia a Favor da Política Social. XVI Congresso de Contabilidade. Goiânia: 2000.

CAMARGO, Mariângela Franco de; SUZUKI, Fabiana Mayumi; UEDA, Mery; SAKIMA, Ricardo Yuzo; GHOBRIL, Alexandre Nabil. Gestão do Terceiro Setor no Brasil. São Paulo: Ed. Futura, 2001.

CARVALHO, Luis Carlos de. Balanço Social. Revista Trevisan, n.143, 2000.

D’AMBROSIO, Daniela. Investir em ética pode ser um bom negócio. Gazeta Mercantil. São Paulo: 27 de julho de 1998. C-8.

DE LUCA, Márcia Martins Mendes. Demonstração do Valor Adicionado. São Paulo: Atlas, 1998.

GONÇALVES, Ernesto Lima. Balanço social da empresa na América Latina. São Paulo: Pioneira, 1980.

HUMES, Dom Cláudio. O Balanço Social nas Empresas. O Estado de S.Paulo, 3/11/99

IUDÍCIBUS, Sérgio de, et alli. Manual de Contabilidade das Sociedades por Ações. São Paulo Atlas,5o ed. 2000.

JUNQUEIRA, Eduardo. A Rotina da Solidariedade. Revista Época, edição 75, 25/10/99

KROETZ, Cesar Eduardo Stevens. Auditoria do balanço social. Revista Brasileira de Contabilidade, n. 116, mar/abr. 1999.

MARTINS, Eliseu. Balanço Social - Idéia que merece permanecer. Jornal Gazeta Mercantil, São Paulo, 18 set. 1997.

OREM, Bernadette Coser de. Responsabilidade Social Empresarial. A Gazeta (ES) - 23/11/99 
SUCUPIRA, João. A responsabilidade social das empresas. www.ibase.org.br, 7/06/02.

SUPLICY, Marta. Artigo publicado em 10 de junho. Folha de São Paulo, 1997.

TORRES, Ciro. Balanço Social: Cidadania e Transparência Pública das Empresas, Ibase, 1999.

ECONÔMICO, Valor. Editorial: Ação social, investimento com dividendos garantidos. Ano 3, No 526, $1^{\circ}$ Caderno. 11 de junho de 2002.

www.balancosocial.org.br, 1/06/02

www.bsr.org, 20/06/01

www.ethos.org.br, 17/06/01

www.filantropia.org, 29/06/01

www.ipea.gov.br, 13/06/02 